\title{
INTERDISCIPLINARY WORK OF THE INTERNATIONAL SPECIALIST SCHOOL FOR PREVENTION, TREATMENT, AND REHABILITATION OF ADDICTIVE DISEASES. EDITORIAL*
}

For more than a decade the European Center for Peace and Development has been organising the International Specialist School (hereinafter: School) with a focus on contemporary achievements in the prevention and treatment of addiction. Considering that this is primarily the product of a long-term exchange of knowledge and experience of experts in the field of psychiatry from the former Yugoslavia, who deal mainly with the problem of addiction on the basis of their own clinical practice, the need has been highlighted to open the School to other scientific disciplines by involving scientists from the socio-humanistic field, as well as to relevant civil society organisations. As a result, the $11^{\text {th }}$ edition of the School held in Kotor (Montenegro) in June 2019 included in the programme several presentations by sociologists, anthropologists and representatives of associations of treated alcoholics and Croatian Red Cross. Furthermore, a round table entitled "Dialogue between Clinical Addictionologists and Sociologists" has put forward several proposals on the topics of future research and interdisciplinary cooperation.

However, it turned out that, despite mutual respect and understanding professional limitations in the study of the addiction phenomenon, differences in approaches can be identified not only in the terms used by separate disciplinary frameworks, but within them as well. This applies already to the basic terms such as addiction, drugs and their use - it is obvious they are not neutral and do not derive from the substances themselves, but rather suggest the way in which competent social institutions observe these phenomena. In other words, these terms reflect the discourse and the power to create a reality by naming it and giving it a meaning. Since a significant part of the School's participants is professionally engaged in the treatment of addictions, it is understandable that this phenomenon is approached in terms of a disease, by varying the meaning of this determination through the respect for diversity, but also uniformity of the clinical practice experience. However, a space for discursive patterns of the addiction phenomenon reality has been opened up, resulting from different professional and institutionally based experiences, by no means less real, nuanced, and uniform, like those framed by the harm-reduction activism or academic and extra-academic, cabinet and field (ethnographic) research work.

The mentioned round table showed that "dialogue" is not a one-time event, but rather needs to be systematically and benevolently nurtured over a longer period of time. So, through the work of the School and through the communication that followed thereafter, the idea was developed to highlight the focus of the upcoming 2020 School through the subtitle "A Move towards Interdisciplinarity" and in the meantime to 
enable the interested participants to convert their 2019 presentations into articles. The articles published in this number of the INDECS journal have undergone a review process and ultimately received two positive reviews. This thematic number of the INDECS journal features five articles that reflect the cooperation between psychiatrists, sociologists, psychologists, and harm-reduction activists.

The first article (Development of the Family System-therapeutic Approach in the Addictions Treatment in Serbia) deals with the historical development of medical alcohology in Serbia and elaborates the process of theoretical and practical deconstruction of the moral approach to alcoholism. In addition, the theoretical features of the systemic approach are elaborated in a detailed way, which enables the understanding of its transformation into a diagnostic tool and its integration into therapeutic practice.

Using a similar approach, the second article (Comparison of the Development and Functioning of Addiction Treatment System in Croatia) presents an overview of the situation and the development in the field of professional engagement with the problem of addiction in Croatia and outlines the basic specificities in the historical development of this disciplinary field in Croatia, implying the basic characteristics and differences among the three basic types of addiction (alcohol addiction, drug addiction, and gambling addiction). These types do not only coincide with wider changes in the development of Croatian society at certain points in time but also open up the space to continually redefine the overall phenomenon of addiction and to reflect on new therapeutic strategies.

The third article (The Role of Social Integration in the Clubs of Treated Alcoholics in Croatia) presents a further investigation of the rehabilitation system regarding alcoholism in the Republic of Croatia. The possibilities for the sociological study of alcoholism as a disease in terms of a functionalist perspective are elaborated, which is evident in the conceptual reliance on the Parsons model of the sick role. In this way, an opportunity is opened to further elaborate the sociological contributions to issues that have been previously raised by social epidemiology.

The fourth article (Cultural Patterns of Alcohol Consumption and Alcoholism in the North and South of Croatia) also focuses on the phenomena of alcohol consumption and alcoholism but from the anthropological point of view. Authors present cultural practices and statistics related to alcohol consumption and alcoholism problems in the context of the Republic of Croatia. In the paper, there is a special focus on gender differences in alcohol consumption and on how these differences are reflected across a plurality of cultural spaces in Croatia.

Finally, the fifth article (A Sociohistorical Overview of Harm Reduction Development in Croatia) deals with the basic determinants of the social and cultural context in the development of needle exchange programmes in Croatia over the past three decades. The article suggests the possibility of critically examining earlier canonical explanations for drug use based mainly on anomaly and disorganization theories, and 
highlights the importance of decentralisation and social sensitivity in the process of implementation of the harm-reduction programme and its incorporation into the prohibitionist framework of the current government's drug policy.

Basically, all these articles are an elementary basis to further develop the interdisciplinary dialogue initiated in the work of the School last year and enable a clearer presentation of the theoretical and epistemological assumptions about addiction and drug use through their contents, selected topics and presented current scientific and research activities.

\section{Cordially,}

Zagreb, $15^{\text {th }}$ March 2020

Guest editors:

Nikša Dubreta

Erik Brezovec 